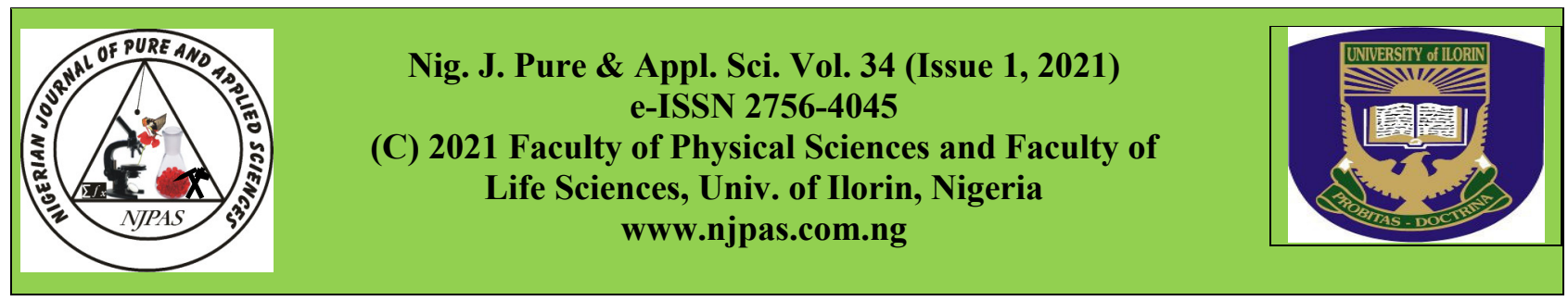

http://dx.doi.org/10.48198/NJPAS/19.B12

\title{
Development of a Push-Type Liquid Fertilizer and Pesticide Sprayer
}

${ }^{* 1}$ Busari, R. A., ${ }^{1}$ Fadeyibi, A., ${ }^{2}$ Akpenpuun, T. D. and ${ }^{1}$ Issah, A. M.

Page | 3851

${ }^{1}$ Department of Food and Agricultural Engineering, Kwara State University, Malete

${ }^{2}$ Department of Agricultural and Biosystems Engineering, University of Ilorin, Ilorin, Nigeria

\section{ABSTRACT}

Low yield, insect, pest and weeds competing with crops are challenges in crop production systems in Nigeria. This research was carried out to design and developed a push-type wheel operated liquid fertilizer/pesticide sprayer. The materials used for fabrication were selected based on the design assumptions, calculations and sourced locally. The sprayer was mechanically operated through the rotating shaft of the cartwheels using a slider-cranks mechanism. An accumulator was provided to create the required pressure of continuous spraying action. The sprayer possesses two tanks of $16 \mathrm{~L}$ each, a wheel, a coup-able stand, eight nozzles and an adjustable height depending on the crop height. The sprayer can cover 4.8 hectares per day, effective field capacity of 1.13 $\mathrm{ha} / \mathrm{h}$, theoretical field capacity of $1.24 \mathrm{ha} / \mathrm{h}$. and field efficiency of $91 \%$. The developed sprayer consumes less time, cost effective, high efficiency and the users will just have to pull the cart and the whole mechanism will be operated with ease.

Keywords: Slider-crank mechanism, Design, Nozzle, Field capacity, Efficiency.

\section{Introduction}

Activities of insects and pests are largely responsible for the low crops yields in Nigeria. Pesticides and insecticides are used to kill crops destroyers or curtail their growth rate. The application of liquid fertilizers, insecticides, herbicides and pesticides are done with the aid of sprayers. The advantages of using sprayers for chemical application, include, capability of applying at the desired level, ease to operate, little or zero maintenance, enhancement of uniform distribution of the contents, precision made nozzle tips for adjustable stream depending on crop requirement (Shivaraja and Parameswaramurthy, 2014).

Presently, Nigeria farmers uses lever operated backpack type sprayer that require constant pumping to operate, which may affect the muscles of the operators. This type of manual sprayer is associated with drudgery, laborious and time consuming. In addition, very small area of land can be covered using backpack sprayer. Over time, farmer experience bark pain as a result of the constant use of the sprayer. Other demerits of using the backpack type liquid sprayer were the emission

Corresponding Author: Busari, R.A.

Department of Food and Agricultural Engineering, Kwara State University, Malete. Email: rasheed.busari@kwasu.edu.ng 
of harmful gases like the carbon-dioxide to the environment. This, apart from causing detrimental effect on the human health, it could affect the general stability of the environment (Issah, 2019). Several researches on the modifications of Page | 3852 convectional sprayers have been undertaken in the past. For instance, Anibude et al. (2016) developed animal drawn hydraulic boom sprayer with $100 \mathrm{~L}$ spray tank capacity, operator seat, ten flat fan nozzles, mainframe, piston pump, 3hp petrol engine, wheel and axle shaft. Portable petrol engine was used as source of power for operating the pump during spraying and pair of bullocks were used for hauling purpose. Application rate of the sprayer was $260 \mathrm{~L} / \mathrm{ha}$, effective field capacity of $1.04 \mathrm{ha} / \mathrm{h}$, theoretical field capacity of $1.16 \mathrm{ha} / \mathrm{h}$, and field efficiency of $89.6 \%$. The results obtained was compared with the manually operated knapsacks sprayer represents $62 \%$ and $37 \%$ increase in effective field capacity and field efficiency, respectively. The authors reported an improvement of the manually operated knapsack sprayer, but the operator must purchase fuel for its operation and increase the running cost of operating the sprayer.

Shivaraja and Parameswaramurthy (2014) developed a wheel operated pesticide sprayer that consumes less time and avoids the pesticide coming in contact with the operator. The wheel and pedal operated sprayer use reciprocating pump with an accumulator to provide a continuous flow of fluid to create adequate pressure for the spraying action. But, the rough surface of the cultivated farmland limits the smooth running of the pedal sprayer. Dileep et al. (2017) develop pedal operated multipurpose bicycle with sprayer and water pump. The setup was portable and mounted on a bicycle. The pedal operation of this cycle is use as mobility and the same time for spraying the chemicals. The time of operation depends upon the efficiency of this reciprocating pump used to lift the water. The mechanism was reliable and useful in the rural areas to get sufficient source of power and the dual ability makes it more special. This type of sprayer is however limited because of the need to constantly paddle the wheel of the bicycle. Abayineh (2016) developed animal drawn chemical sprayer which was operated by a diesel engine. The chemical distribution process is usually regulated with help the nozzle and the walking speed of the animal. The chemical sprayer is operated by a single animal, the sprayer tank and diesel engine are mounted on the sheet metal platform, which is operated by draft power of the animal. The spray swath width of $7.5 \mathrm{~m}$ length is provided with fourteen numbers of hollow cone nozzles which are adjustable according to row spacing of crop. The wheels of sprayer are adjustable according to row spacing of different crops and the unit is provided with a plastic tank of $150 \mathrm{~L}$ capacity. The design required fuel for its operation which in turn increase the running cost and power is also involved. To address some of the challenges associated with pervious sprayer there is need to develop and design a push-type operated liquid fertilizer sprayer. The objective of this research is to develop a push-type liquid fertilizer sprayer.

\section{Materials and Methods Assumptions used in the Design}

i. The wheel is designed to maneuver only on a soil with low moisture content.

ii. Two tanks each having a capacity of $16 \mathrm{~L}$ was allowed for maximum chemical application.

iii. The machine will be a second order lever, where the fulcrum, load and force are the wheel, tank and handle for push-force application, respectively.

iv. It is assumed that a grown-up human being uses an average power of $0.1 \mathrm{~kW}$, a torque of $15 \mathrm{kN}-\mathrm{m}$, speed of $30 \mathrm{rpm}$ and allowable time of $2 \mathrm{~h}$ (Onwualu et al., 2006). 


\section{Components of the Push Type Sprayer and Materials Used}

The various parts/components of the machines and materials used were listed in Table 1.

Page | 3853 Table 1: Components and Materials Used

\begin{tabular}{cll}
\hline S/N & Components & Materials used \\
\hline 1. & Tank & Plastic \\
2. & Nozzles & Plastic \\
3. & Pipe and hose & Plastic \\
4. & Sprocket and chain & Treated steel \\
5. & Frame & Mild steel $(2 \times 2$ angle iron $)$ \\
6. & Handle & Round steel pipe \\
7. & Sprayer stand & Mild steel $(2 \times 2$ angle iron $)$ \\
8. & Shaft & Treated steel \\
9. & Wheel & Pneumatic spoke wheel \\
10. & Boom & Metal pipe \\
11. Boom support & Round steel pipe \\
12. Slider crank mechanism Steel \\
13. Eccentric Disc & Circular steel plate
\end{tabular}

\section{Sprayer Tank}

Two tanks were purchased from the Federal Ministry of Agricultural and Rural Development National Headquarter Abuja, Nigeria. The tanks were manufactured by Taizhou Guangfeng Plastic Co., Ltd China. The tanks possess an inbuilt pumping system that when reciprocated will cause a relative release of fluid through the outlet hose. The function of the spray tank is simply to hold a suitable quantity of spray material for delivery to the spray pump. Table 2 shows the specifications of the tanks that were procured from the market.

Table 2: The Tank Specifications

\begin{tabular}{cll}
\hline S/N & Tank components & Specification \\
\hline 1. & Tank capacity & 32 L (16 litres each $)$ \\
2. Head type & Double conical \\
3. Pressure & $0.2-0.4 \mathrm{MPa}$ \\
4. Flow Rate & $1.3-1.6 \mathrm{~L} / \mathrm{min}$ \\
5. Hose length & $1,350 \mathrm{~mm}$ \\
6. Net weight & $3.3 \mathrm{~kg}$ \\
\hline
\end{tabular}

\section{Performance Index}

\section{Actual Field Capacity of the Designed Sprayer}

The actual field capacity was calculated using Equation (1) as reported by Sharma and Mukesh (2010). For the actual field capacity, the time taken for actual work and time lost for other activities such as filling of tank and turning were considered. The time required for real operation and time lost were measured.

$$
\text { Actual Field Capacity }=\frac{A}{\text { Total Time Taken }}
$$

where;

$$
\mathrm{A}=\text { area covered, } 1 \text { ha }
$$

Total Time Taken $=$ time of refilling the tanks + time of turning + time of actual work

Total Time Taken $=3.4 \mathrm{~min} .+1.11235 \mathrm{~min} .+48.4$ $\min =52.9 \mathrm{~min} .=0.8817 \mathrm{hr}$.

$$
\text { Actual Field Capacity }=\frac{1.0}{0.8817}=1.13 \mathrm{ha} / \mathrm{h}
$$

\section{Theoretical Field Capacity}

The theoretical field capacity was calculated using Eqn. (2) as reported by Sahay (2008).

$$
\mathrm{TFC}=\frac{\text { Speed } \times \text { Sprayer widt }}{10}
$$

Speed $(\mathrm{km} / \mathrm{h})=$ wheel diameter $(\mathrm{cm}) \times$ operator speed $(\mathrm{rpm}) \times 0.001885$

Wheel diameter $=60 \mathrm{~cm}$, operator speed $=30 \mathrm{rpm}$

speed $=60 \times 30 \times 0.001885=3.393 \mathrm{~km} / \mathrm{h}$

Sprayer width $=3.66 \mathrm{~m}$

$$
\mathrm{TFC}=\frac{3.393 \times 3.66}{10}=1.24 \mathrm{ha} / \mathrm{h}
$$

\section{Field Efficiency}

Field efficiency was calculated using the expression in Eqn. (3). 


$$
\text { F. } E=\frac{\text { Actual Field Capacity }}{\text { Theotrical Field Capacity }} \times 100
$$

where,

\section{$\mathrm{FE}=$ Field Efficiency}

$$
\text { Field Efficiency }=\frac{1.13}{1.24}=0.9113
$$

The field efficiency of the designed sprayer is $91 \%$

\section{Description of the Machine}

The designed sprayer consists basically of the main frame, spray tanks, pump, traction wheel, nozzles, and flexible rubber hose. The main frame is mounted on a stand with single traction wheel and carries the spray tanks and integration pumps with eight spraying nozzles. The spray tank is connected to the boom with the aid of distributing flexible rubber hose via the integrated piston pump. The frame is designed in the way that the height could be adjusted according to crop height between $30 \mathrm{~cm}$ $-120 \mathrm{~cm}$ above the ground. The chemical in the spray tank is pumped to the flexible hose by the piston pumps integrated with the tank. The pump is actuated by an offset slider-crank mechanism, which gets its power from the ground wheel. During the operation, the operator simply puts the machine in a horizontal position and pushes the sprayer into the cultivated plot of the land. While pushing using the handle, the ground wheel transferred power to the attached driving sprocket which in turn drives a smaller sprocket that is attached to a shaft through the chain drive. The rotary motion of the smaller sprocket then converted into the reciprocating motion by the single slider crank mechanism, which actuates the single acting reciprocating piston of the pump installed in the tank pumping the liquid to the boom. The designed hand-push type sprayer is presented in Figure 1.

\section{Machine Evaluation}

The field test was conducted on one hectare of land at Teaching and Research Farm, Kwara State University Malete at longitude $8.71^{\circ} \mathrm{N}$ and latitude $4.47^{\circ} \mathrm{E}$ of the equator. The nozzle discharge was carried out to evaluate the amount of liquid discharge from each of the nozzle and to check the variation between the discharge rates of each nozzle within 100 meters. The discharge from each of the nozzle were collected using nylon bag attached to each nozzle, as shown in Figure 2. Discharge data was collected, and time taken was recorded for each trial test, using the stopped watch. The test was repeated twice, after each $100 \mathrm{~m}$ interval the designed sprayer was stopped, and each liquid collected from the nozzle were measured using calibrated measuring cylinder. Figure 2 shows the testing of the nozzle discharge rate and obtained results of discharges from various nozzles were recorded in liters/minutes.

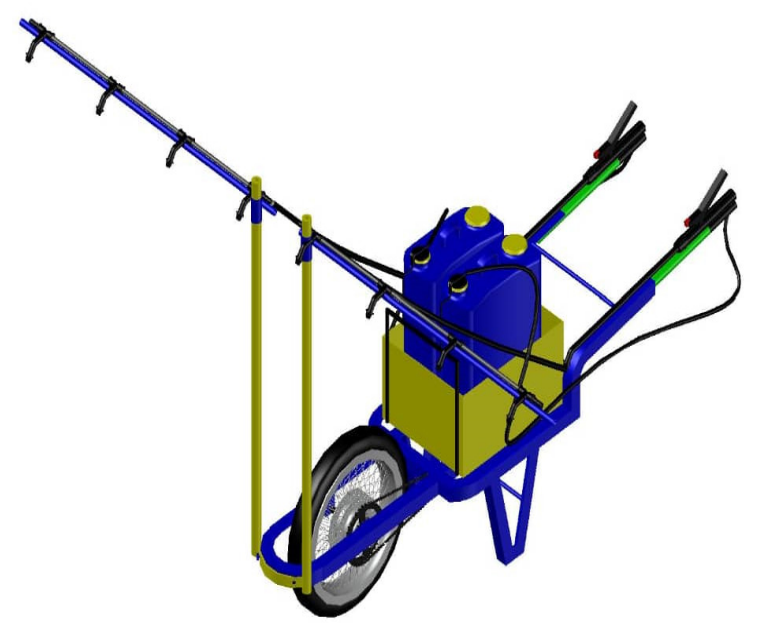

Figure 1: Designed hand-push type sprayer

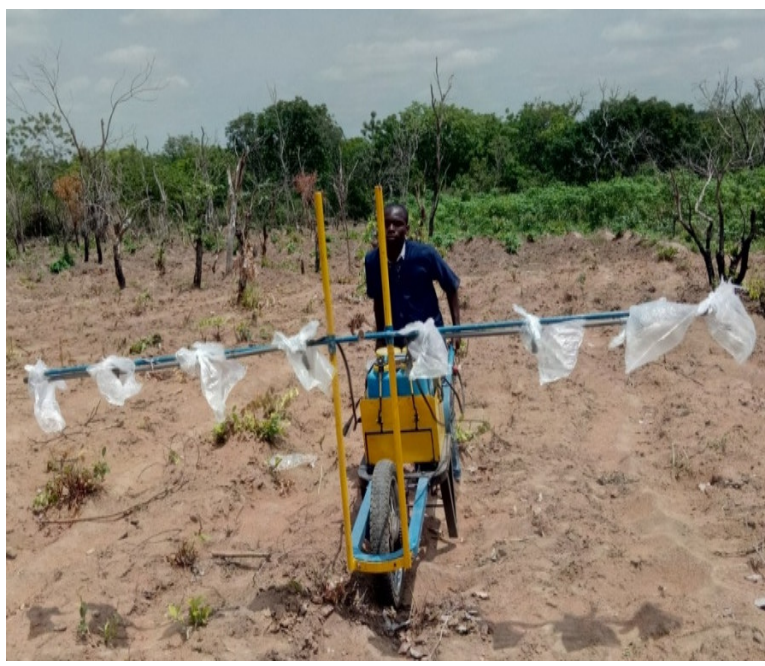

Figure 2: Designed Sprayer discharge per nozzle 


\section{Results and Discussions}

The result obtained from the performance of the designed machine is presented in Table 3. The farm size, evaluation time, spray pressure, discharge rate, Page | 3855 operator speed, actual field capacity, theoretical field capacity and field efficiency were evaluated and recorded in Table 4.

Table 3: Discharge per Nozzle

\begin{tabular}{lll}
\hline $\begin{array}{l}\text { Numbers } \\
\text { of nozzles }\end{array}$ & $\begin{array}{l}\text { Discharge } \\
\text { (L/min) 1 }\end{array}$ & $\begin{array}{l}\text { Discharge } \\
\text { (L/min) 2 }\end{array}$ \\
\hline N1 & 0.630 & 0.635 \\
N2 & 0.570 & 0.570 \\
N3 & 0.625 & 0.625 \\
N4 & 0.405 & 0.405 \\
N5 & 0.640 & 0.645 \\
N6 & 0.610 & 0.610 \\
N7 & 0.520 & 0.525 \\
N8 & 0.420 & 0.410 \\
Average & $\mathbf{0 . 5 5 1}$ & $\mathbf{0 . 5 5 3}$ \\
\hline
\end{tabular}

$\mathrm{N} 1, \mathrm{~N} 2 \ldots \mathrm{N} 8$ are eight sprayer nozzles fitted on the boom at $30 \mathrm{~cm}$ spacing

Table 4: Performance Parameters of the Designed Sprayer

\begin{tabular}{rlr}
\hline S/N & parameters & Values \\
\hline & Functional & \\
1. & Number of nozzle and spacing, $8 \times 30 \mathrm{~cm}$ \\
& cm & \\
2. & Sprayer width, $\mathrm{m}$ & $2.4 \mathrm{~m}$ \\
3. & Width covered by sprayed & $3.6 \mathrm{~m}$ \\
& nozzles & \\
& Performance
\end{tabular}

\begin{tabular}{lll} 
4. Quantity of liquid sprayed, 1 & \\
5. Effective time, (min) & 48.4 \\
6. Lost time, min & 4.51 \\
7. Total time, min & 52,9 \\
8. Field size or Area treated, ha & 1.0 \\
9. Forward speed, $\mathrm{km} / \mathrm{hr}$ & 3.393 \\
10. Actual field capacity, $\mathrm{h} / \mathrm{hr}$ & 1.13 \\
11. Theoretical field capacity & 1.24 \\
12. Field efficiency, \% & 91.13 \\
\hline
\end{tabular}

The average discharge rate varies from 0.42 to 0.64 $\mathrm{L} / \mathrm{min}$. with the average discharge of $0.55 \mathrm{~L} / \mathrm{min}$.
Operation pressure of $0.2 \mathrm{MPa}$ was observed at the forward speed of $3.39 \mathrm{~km} / \mathrm{hr}$. The sprayer operating pressure was maintained constant as the machine advances getting the traction force from the ground. The amount of liquid sprayed was $33.13 \mathrm{~L} / \mathrm{ha}$, which gave an application rate of $265.05 \mathrm{~L} /$ day. In addition, the actual field capacity was calculated to be $1.13 \mathrm{ha} / \mathrm{h}$ while the theoretical field capacity was $1.24 \mathrm{ha} / \mathrm{h}$. The machine efficiency of $91.13 \%$ was achieved and good uniformity of spray was also observed and refilling time of 1.5 times per hectare. The result obtained is an improvement over the research findings of Mulatu, (2018), who reported the sprayer designed tank capacity of 20 litres, whose full tank can cover an area of $0.07 \mathrm{ha}$, with refilling time of 14 times to cover one hectare with an application rate of $281 \mathrm{~L} / \mathrm{ha}$ and an average discharge rate $13.04 \mathrm{ml} / \mathrm{s}$. The difference may be, as result of design capacity and spraying mechanism. Comparing the application rate of the designed sprayer with that of the conventional knapsack sprayer, as reported by Malik et al. (2012) that the application rate of the knapsack as 0.4 ha/day and field efficiency of $56 \%$ was reported. The designed sprayer has better efficiency and application rate than the existing back type of Knapsack sprayer. The new sprayer has enhanced capacity, eliminate drudgery associated with the existing sprayer and less spraying time. It does not require fuel to operate. Also, larger cultivated area can be covered in a day since the sprayer has eight nozzles. The sprayer is easy to move and sprays chemicals by moving the wheel and work reliability under different working conditions.

\section{Conclusions}

The designed sprayer addressed some of the challenges associated with convectional sprayer and more nozzles (eight) which cover large area of farmland in a lesser time. Height adjuster was incorporated to the designed sprayer to give room for spraying at different crop/plant height. Therefore, excessive use of pesticides or insecticides is avoided. The machine also eliminate 
drudgery associated with operation of lever and can be used for multiple crops/plants. The designed machine is easy to operate and the pumps deliver the liquid at adequate pressure with the nozzle output of $0.55 \mathrm{~L} / \mathrm{min}$. with spray width of $3.6 \mathrm{~m}$. The

Page | 3856 machine is economical and cost effective which can be affordable to all kind of local farmers. Lesser time is required for spraying more hectares per day and no fuel required and maintenance cost is low. It is noiseless, eco-friendly and doesn't produce vibration. The construction is simple and not as difficult as other sprayers types. It is simple to use and easy to manufacture. The sprayer is designed with tank capacity of $32 \mathrm{~L}$, a full tank can cover an area of 0.96 ha, with refilling time of 1.5 times per hectare and application rate of $265.05 \mathrm{~L} /$ day and sprayer can cover 4.8 hectares per day, effective field capacity of $1.13 \mathrm{ha} / \mathrm{h}$, theoretical field capacity of $1.24 \mathrm{ha} / \mathrm{h}$. and field efficiency of $91.13 \%$.

\section{Competing interests}

Authors have declared that no competing interests exist.

\section{References}

Abayineh, A. (2016). "Development and Performance Evaluation of Agricultural Chemical sprayer For Ethiopian Animal Power Case; International Journal of Engineering Research online A Peer Reviewed International Journal; 4 (1): 23217758

Anibude, E.C (2016). Development of an Animal Drawn Hydraulic Boom Sprayer; American Journal of Engineering Research (AJER); 5 (2): $222-228$

Dileep, K.J., Hussain, M., Geetha, S. and Vishweshwarayya. A. (2017). Pedal Operated Multipurpose Bicycle with Sprayer and Water Lifting Pump; International Journal of Latest Engineering Research and Applications (IJLERA); 2 (5): 1 - 9, ISSN: 2455-7137

Issah, A.M. (2018). Development of a Push-Type Operated Liquid Fertilizer/Pesticide Sprayer; Unpublished B.Eng. project, Department of Food and Agricultural Engineering, Kwara State University Malete, Nigeria.

Mulatu, Y. (2018). Design, Construction and Performance Evaluation of Ground Wheel Driven Wheelbarrow Boom Sprayer; $A$ thesis Submitted to program of Mechanical systems and Vehicle Engineering School of Mechanical, Chemical and Material Engineering in Partial Fulfillment of the Requirement for Acquired the Degree of Master of Science in Agricultural Machinery Office of Graduate Studies Adama Science and Technology University.

Onwualu, A.P., Akubuo, C.O., Ahneku, I.E. (2006) Fundamentals of engineering in agriculture. Immaculate Pub.Ltd, Lagos, Nigeria, $\mathrm{p}$ 259-262

Poudel, B., Sapkota, R., Shah, R.B., Subedi, N., Krishna, A. (2017). Design and Fabrication of Solar Powered Semi -Automatic Pesticide Sprayer; International Research Journal of Engineering and Technology (IRJET): 4(7): 2074 - 2077.

Sharma and Mukesh, S. (2010). Farm machinery design principles and problems, Sunikumarjani for Janibrothers, New Delhi 110005.

Shivaraja, k. and Parameswaramurthy, D. (2014). Design and Development of Wheel and Pedal operated Sprayer; IPASJ International Journal of Mechanical Engineering (IIJME); 2(6) ISSN 2321-6441 